\title{
NeuroImage
}

\section{Overt and imagined singing of an Italian aria}

\author{
B. Kleber, ${ }^{a, *}$ N. Birbaumer, ${ }^{a, b}$ R. Veit, ${ }^{a}$ T. Trevorrow, ${ }^{c}$ and M. Lotze ${ }^{a, d}$ \\ anstitute of Medical Psychology and Behavioral Neurobiology, University of Tübingen, Germany \\ ${ }^{\mathrm{b}}$ National Institute of Health (NIH), NINDS, Human Cortical Physiology Section, Bethesda, USA \\ ${ }^{\mathrm{c}}$ Chaminade University of Honolulu, Behavioral Sciences, Honolulu, USA \\ ${ }^{\mathrm{d}}$ Department of Functional Imaging, Center for Radiology, University of Greifswald, Germany
}

Received 29 November 2006; revised 20 February 2007; accepted 23 February 2007

Activation maps of 16 professional classical singers were evaluated during overt singing and imagined singing of an Italian aria utilizing a sparse sampling functional magnetic imaging (fMRI) technique. Overt singing involved bilateral primary and secondary sensorimotor and auditory cortices but also areas associated with speech and language production. Activation magnitude within the gyri of Heschl (A1) was comparable in both hemispheres. Subcortical motor areas (cerebellum, thalamus, medulla and basal ganglia) were active too. Areas associated with emotional processing showed slight (anterior cingulate cortex, anterior insula) activation. Cerebral activation sites during imagined singing were centered on fronto-parietal areas and involved primary and secondary sensorimotor areas in both hemispheres. Areas processing emotions showed intense activation (ACC and bilateral insula, hippocampus and anterior temporal poles, bilateral amygdala). Imagery showed no significant activation in A1. Overt minus imagined singing revealed increased activation in cortical (bilateral primary motor; M1) and subcortical (right cerebellar hemisphere, medulla) motor as well as in sensory areas (primary somatosensory cortex, bilateral A1). Imagined minus overt singing showed enhanced activity in the medial Brodmann's area 6, the ventrolateral and medial prefrontal cortex (PFC), the anterior cingulate cortex and the inferior parietal lobe. Additionally, Wernicke's area and Brocca's area and their homologues were increasingly active during imagery. We conclude that imagined and overt singing involves partly different brain systems in professional singers with more prefrontal and limbic activation and a larger network of higher order associative functions during imagery.

(C) 2007 Published by Elsevier Inc.

Keywords: Auditory imagery; Singing; Audio-motor; Musicians; fMRI

\footnotetext{
* Corresponding author. Institut für Medizinische Psychologie und Verhaltensneurobiologie, Eberhard-Karls-Universität Tübingen, Gartenstraße 29, D-72074 Tübingen, Germany. Fax: +49 7071295956.

E-mail address: boris.kleber@uni-tuebingen.de (B. Kleber).

Available online on ScienceDirect (www.sciencedirect.com).
}

\section{Introduction}

Performing music in one's mind is a technique commonly used by professional musicians to rehearse various aspects of a musical piece, e.g. difficult parts of an already executed musical passage (Lotze et al., 2003). Composers write their music regardless of the presence of a musical instrument, as for example Schubert or Mozart did routinely. Beethoven composed his violin concerto in D-major (op. 61) even though he was already deaf and famous musicians like Vladimir Horowitz and Walter Gieseking reported frequent use of mental practice (Gieseking and Leimer, 1972; Schonberg, 1987). Several experiments have proven the benefits of motor imagery in motor skill learning and its use as a tool to probe the neural basis of overt motor performance is increasingly appreciated (e.g. Langheim et al., 2002; Yue and Cole, 1992). The training of auditory imagery has shown to improve harmony skills in children (Humphreys, 1986) and Highben and Palmer (2004) demonstrated that the ability of pianists to learn an unfamiliar piece without auditory feedback depend on their degree of aural skills (e.g. the ability to perceive melodic differences). PascualLeone (2003) proved that mental practice has not only the capacity to improve performance it also changes the size of the cortical representation of the motor cortex over time. Motor imagery can improve the dynamics of motor performance (Yaguez et al., 1998) and the velocity and smoothness of sequential movements trajectories (Lacourse et al., 2005). Yet mental music rehearsal does not only include motor, kinesthetic and auditory imagery but also emotional aspects of the piece rehearsed, which involves three components: a semantic meaning component, a stimulus component and a response component that defines the imagined emotion (Lang, 1979). Emotional memory retrieval therefore represents an associative network processing that may reflect a prototype of a propositional network in the brain for overt responding.

Singing in the field of classical music involves both technicalmotor and a strong emotional engagement in order to transport the musical intention and to communicate artistic, emotional and semantic aspects of the song or aria. Whilst classical singing shares some aspects with speech: i.e. articulation and movements of the vocal tract, expression of meaning, reading or recalling words and prosodic modulation of the voice, other elements are quite 
different. These involve the stylistic accuracy demanded in classical singing (e.g. in German Lied, Baroque music or Late Romantic opera), the tight regulation of musical pitch, meter and rhythm as well as an increased sound intensity and vocal range, vibrato and an emphasized dramatic expression of emotions. Such behaviors require a much higher level of vocal control compared to speech (e.g. Natke et al., 2003). Motor aspects of these requirements are reflected in the finer laryngeal motor control (e.g. for accurate intonation), the appropriate adjustment of the resonating vocal tract (affecting for example timbre and vocal quality) and the high involvement of the diaphragm and the thoracic muscles for a precise control of the airflow during singing (Watson and Hixon, 1985). However, studies investigating cerebral correlates of singing are sparse and focus on non-musicians.

A first fMRI-study that investigated silent singing in musically non-trained subjects demonstrated a lateralization of the motor representation of the tongue area to the right during singing in comparison to a left lateralization during speech (Wildgruber et al., 1996). The first study of overt singing used Positron Emission Tomography (PET) in subjects with musical training less than 1 year. Cerebral activation during singing of pitch and spoken vowels was compared (Perry et al., 1999) and activity in motor areas (primary and secondary; cerebellar hemisphere in lobule VI), auditory areas (right gyrus of Heschl), the bilateral insula, the medial cingulate cortex, the parietal and occipital lobe and the brain stem was observed. Overt humming of a melody (W.A. Mozart's "Kleine Nachtmusik") compared to word generation revealed cerebral lateralization to the right in the insula and temporal pole and to the left in the cerebellar hemisphere (Riecker et al., 2000). Hickok and colleagues (Hickok et al., 2003) were predominantly interested in audio-motor coupling and compared humming with listening to piano pieces. They reported a left parieto-temporal and frontal network active during humming. A recent study investigated neural correlates of overt singing and speaking by using the same bisyllabic words/phrases for both conditions in a group of non-professional singers (Ozdemir et al., 2006). They reported a shared network for sensorimotor processes in both singing and speaking, which involved the inferior pre- and post-central gyrus, superior temporal gyrus (STG) and the superior temporal sulcus (STS) on both hemispheres. Singing in comparison to speech revealed a larger network that involved bilateral activations in the anterior to midportions of the STG (enhanced in the right hemisphere) including Heschl's gyrus, but also in the anterior portion of BA 22 and BA 38, the most inferior portion of the inferior frontal gyrus (Broca's region), inferior aspects of the central operculum and the middle and most inferior portions of the sensorimotor cortex, possibly reflecting a greater bihemispheric organization for singing. All of the abovementioned studies were carried out with non-experienced or amateur singers. Studies with professional singers have not yet been published. The assessment may have been limited by artifacts elicited by movements of the head and jaw and changes of air-space during vocalization and articulation (Soltysik and Hyde, 2006). fMRI-techniques controlling for the artifacts produced by overt singing are now available (Gracco et al., 2005; Soltysik and Hyde, 2006) and sparse sampling techniques allow for auditory feedback during singing (Gaab et al., 2003; Ozdemir et al., 2006).

While substantial evidence corroborates the contribution of primary visual cortex during certain visual imagery tasks (Kosslyn and Thompson, 2003), the relative contribution of primary (core) and secondary (belt) auditory areas during auditory imagery is still a matter of discussion (Zatorre and Halpern, 2005). The primary auditory cortex of healthy subjects seems to have "a propensity to spontaneously 'activate' during silence" (Hunter et al., 2006). Primary auditory cortex activation in the absence of auditory input has been found for short gaps of silence (lasting 2-5 s) that were inserted at different points during the soundtrack of familiar music (Kraemer et al., 2005) and in a sound detection task during the preceding silence of the emerging sounds (Voisin et al., 2006). A further report of primary auditory activation during mental imagery of a computer generated monotone $\left(\mathrm{C}^{\mathrm{maj}}\right)$ comes from Yoo and colleagues (Yoo et al., 2001) but a recent inspection of the exact locus of activation indicated in that study questioned their results (Halpern et al., 2004). More compelling evidence exists regarding the contribution of secondary (or association) auditory cortex during mental imagery of complex, meaningful sounds (Bunzeck et al., 2005; Halpern and Zatorre, 1999; Halpern et al., 2004; Shergill et al., 2000; Shergill et al., 2001; Zatorre et al., 1996). These results are supported by studies on imagined musical performances in professional instrumentalists (Langheim et al., 2002; Lotze et al., 2003). We were therefore particularly interested in the involvement of auditory areas during imagined singing of the Italian aria "Caro mio ben" (by Tommaso Giordani). Given the more complex motor pattern for mental imagery of classical singing compared with other imagery tasks used in experimental situations, we expected strong activation of secondary auditory cortex. Due to the combination of lyrics and melody this activation should be represented bilaterally (Zatorre and Halpern, 2005). Furthermore, we expected left temporo-parietal sylvian cortex activation during imagined singing of a classical aria, supporting auditory-motor integration (Hickok et al., 2003).

Imagined singing could be regarded as auditory imagery of a familiar tune. However, mental singing involves not only auditory mental representations but also somatosensory and kinesthetic aspects, which require a declarative knowledge about the different components of the task (Jackson et al., 2001) - a knowledge almost absent in unskilled subjects. Imaging studies on simple motor paradigms confirmed that imagined movements share neural substrates with executed movements in the supplementary motor area (SMA), the dorsal and ventral premotor cortex (PMC) the cerebellar hemispheres and also - to a lesser extent - the primary motor cortex (Lotze et al., 1999; Porro et al., 1996; Sabbah et al., 1995). Using fMRI and TMS, Kuhtz-Buschbeck and colleagues (Kuhtz-Buschbeck et al., 2003) demonstrated that the primary motor cortex contralateral (cM1) to the imagined movements was active during imagery tasks of increasingly complex movements, a result consistent with a previous finding of more prominent involvement of cM1 with performance of complex motor sequences (Gerloff et al., 1998; Lotze et al., 2000a). Furthermore, kinesthetic motor imagery (i.e. to try to feel the sensations that are usually felt in the muscle-tendon complexes when actually executing the movement rather than just visualizing the execution) involved the primary motor cortex to the same extent as motor execution conditions, indicating a comparable activation of this brain structure in both conditions (Caldara et al., 2004). Earlier studies focusing on mental performance in professional instrumentalists however, did not observe significant M1 and S1 activation (Langheim et al., 2002; Lotze et al., 2003). Singing and particularly singing of classical music as compared to instrumental music requires more body-core centered motor and anatomic activity involving muscles and internal organs of vital bodily importance such as respiration, salivation, ingestion, speech and social communication while string instruments and piano playing, investigated in most brain imaging experiments, involves fine control of peripheral muscle groups. Therefore, we propose that imagery of such vital body-centered activity mobilizes the entire motor system (primary, secondary, basal 
ganglia, thalamus, cerebellum, brain stem) while imagery of sensory stimuli frequently used in MR-studies of imagery (see Kosslyn and Thompson, 2003 for an overview) are "capturing" much less vital body-core functions and therefore report less areas activated. In addition, singing is evolutionary older and more genetically primed than instrumental music, constituting the first basic function to express emotive meaning (Brown, 2000; Molino, 2000). Thus, motor and autonomic associative networks are more widespread. Given that singing an aria is highly associated with emotional expression, and perhaps even more so when free from the demands of actual performance, we also expected activation of areas involved in emotional processing such as the amygdalae, hippocampus, temporal poles, anterior cingulate cortex (ACC), anterior insula, ventral striatum and ventrolateral prefrontal cortex (VLPFC) (Koelsch, 2005).

\section{Methods}

Subjects

16 right handed classical singers (4 opera chorus; 4 opera soloists, 8 vocal students; mean age: $31.06 \pm 8.27$ years; range: 20 -
44 years; 5 men) without reported history of neurological or psychiatric disease participated in the study. The average experience of training in singing was $14.06 \pm 7.59$ years; range 7-28 years. Participants took their first professional singing lessons at the average age of $16.91 \pm 3.14$ years and reported an average of 25.73 $\pm 7.26 \mathrm{~h}$ spent with practicing per week during the 3 months before fMRI-scanning. All singers reported experience in mental rehearsal.

The study was approved by the Ethics Committee of the Medical Faculty of the University of Tuebingen. Written informed consent was obtained according to the guidelines of the Declaration of Helsinki.

\section{Task}

We selected six phrases from the first line of the bel canto aria "Caro mio ben" by Tommaso Giordani, each phrase sung separately after a visual signal (see Fig. 1A). This piece was selected since it is commonly well known by classical singers, it involves strong emotional expression, lyrics and melody are easily memorized, all voice types (tenor, soprano etc) can perform it and the vocal demands are such that it could be performed in a scanner

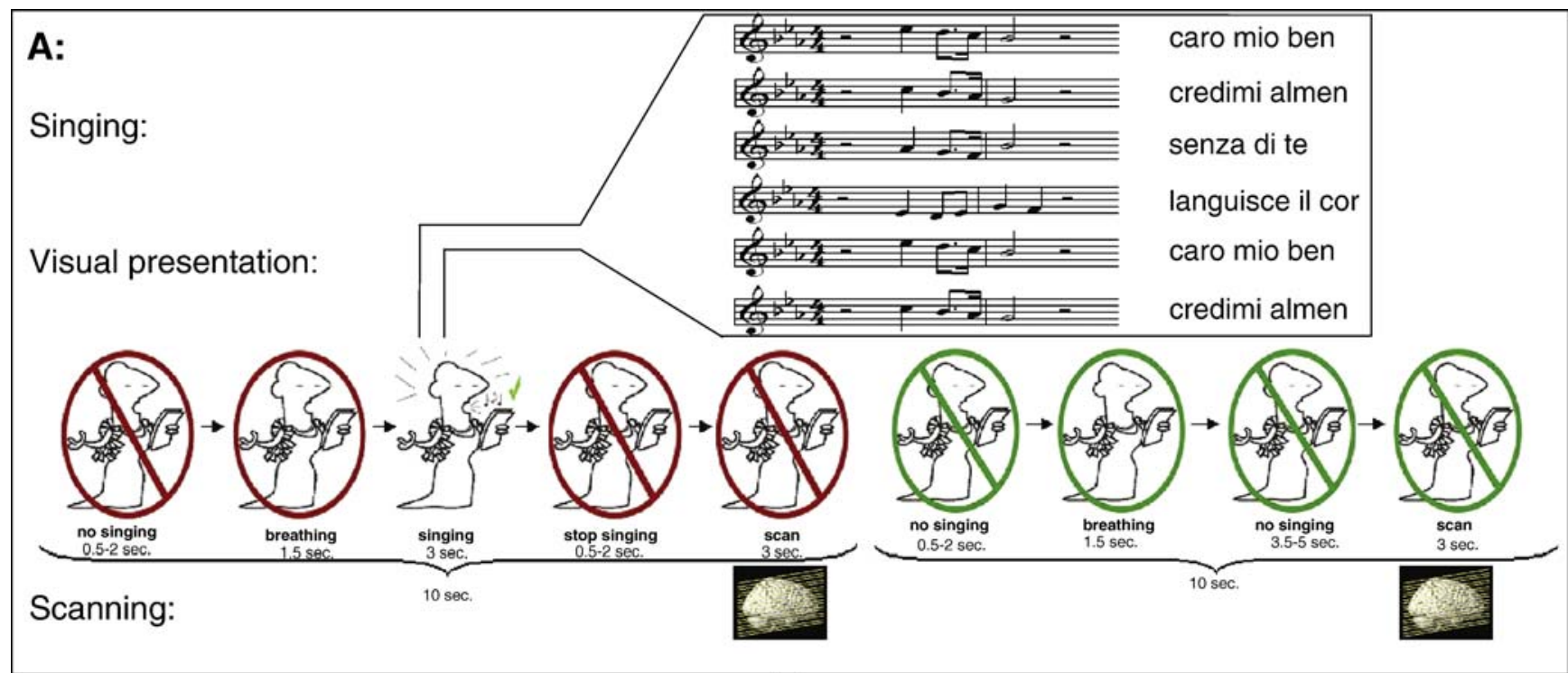

\section{B:}

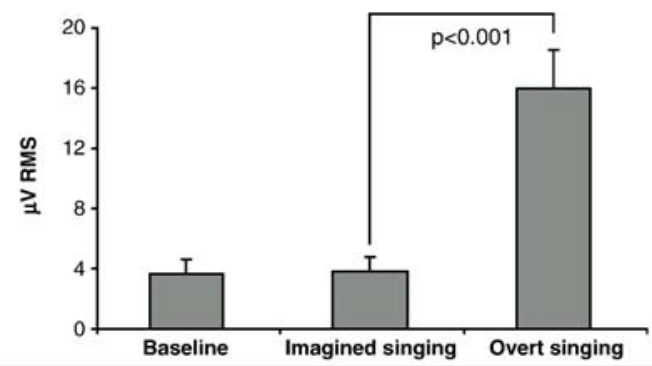

C:

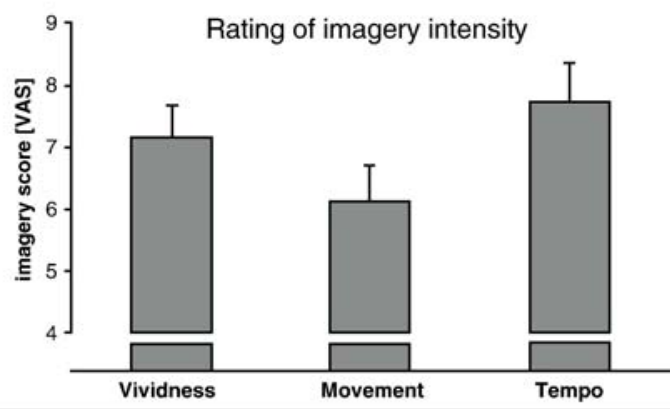

Fig. 1. (A) Design of the procedure. First line: visual signals indicate breathing \& singing during fMRI scans. Red circles for singing blocks (overt and imagined) and green circles for breathing only blocks respectively. Below: Scanning during pausing, for each block 66 scans were performed alternating singing and rest. The imagined singing block was indicated with the same symbols but subjects were instructed to use mental rehearsal instead of overt singing. (B) Superficial EMG amplitudes ( $\mu \mathrm{V}$ root mean square (RMS), 32 samples per second) of musculus cricothyroideus, averaged over $30 \mathrm{~s}$ during baseline (breathing only), imagined singing and overt singing from 10 of the participants recorded outside of the scanner. Baseline and imagined singing did not differ $(t(8)=0.59$; $\mathrm{n} . \mathrm{s}$. $)$ whereas singing versus imagined singing $(t(9)=4.90 ; p<0.001)$ and singing versus baseline differed significantly $(t(9)=4.87 ; p<0.001)$. (C) Rating of imagination intensity (visual analogue score from 0 to 10) by all singers obtained after scanning. Movement rating showed a trend of decreased tempo rating $(t(15)=2.11)$ but this result did not stand correction for multiple comparisons. 
environment without extreme pitches or forti, which might induce additional artifacts. Additionally, the phrase structure of that piece is such that the $3 \mathrm{~s}$ phrases naturally fit the sparse sampling technique employed, which allowed for natural auditory feedback during singing. Phrases were rehearsed before (by B.K.) with recorded scanner sound and were trained again within the scanner for the first six phrases. The overt singing part was followed by the mental rehearsal of singing in distinct sections. In the latter section, subjects sung the same phrases only in their imagination. Six periods of singing (and imagined singing respectively) alternated with six periods of deep inspiration not followed by singing (or imagined singing).

With respect to the imagined singing task, subjects were required to imagine the physical performance of singing as vividly as possible without performing any movements. Concentration, vividness of imagery of singing, singing related movements, tempo and rhythm during the fMRI-scanning was assessed with Visual Analogue Scales (VAS; from $0=$ "not at all" to $10=$ "very good") after each block. Auditory control by microphone during the imagery period did not reveal any sound-production. To test for possible movements of throat muscles involved in overt and imagined singing we recorded surface electromyography (EMG) of the musculus cricothyroideus with the Nexus-10 polygraph (MindMedia, NL) and superficial silver chloride electrodes in 10 subjects during baseline (breathing), mental rehearsal (imagined singing) and (overt) singing (see Fig. 1B). EMG was measured outside of the scanner since EMG-electrodes resulted in substantial artifacts if placed in a head coil. Signals were acquired at 1024 samples per second, bandpass filtered (20-500 Hz; IIR filter, Butterworth 4th order) and sent via Bluetooth to a PC for data visualization, storage and preprocessing using BioTrace Software (MindMedia, NL). EMG amplitudes were calculated (root mean square, epoch size 1/16 s, 32 samples per second (SPS)) and averaged over $30 \mathrm{~s}$ for baseline, imagined singing and singing for each subject. Differences between the three measures were compared with ANOVA followed by paired $t$-tests using the Statistical Package for the Social Sciences (SPSS 10.05).

\section{fMRI technique}

Whole head scans (66 volumes per block) were performed with a 1.5 Tesla whole body Scanner (Siemens Vision) using echo planar imaging (EPI; TE: $40 \mathrm{~ms}$; TR: $3 \mathrm{sec}, 36$ transversal slices of $3 \mathrm{~mm}$ thickness and $1 \mathrm{~mm}$ gap, matrix $64 * 64)$. A sparse sampling method was employed to avoid movement artifacts and to allow auditory control during singing. The first 3 EPI data sets of each session were discarded prior to analysis to allow for T1-saturation effects. T1-weighted images (MPRage; 176 sagittal slices with $1 \mathrm{~mm}$ effective thickness) were measured for anatomical reference. Data were analyzed with the statistical parametric mapping program (SPM99 (for preprocessing and single subject statistics) and SPM2 (random effects group statistics), Wellcome Department of Imaging Neuroscience) running on Matlab (MathWorks Inc; Natick, MA, USA). SPM2 was used for group statistics to allow for non-sphericity correction in case of unequal variances between levels or groups, an option not available in SPM99. Each individual scan was realigned to the first one of each scanning condition to correct for movement artifacts. The realigned data were spatially normalized to the MNI-template and resliced with $3 * 3 * 3 \mathrm{~mm}$. The resulting images were smoothed with a $9 \mathrm{~mm}$ (full width at half maximum) Gaussian filter. Individual statistical maps (fixed effect) were calculated for singing and imagined singing (main effect) and for differences between both. Contrast images of each subject were then used for group statistics calculated as random effects analysis at the 2nd level, which takes variance between subjects into account. The statistical threshold used to report group-activations was set as $p<0.05$ corrected for the whole brain (false discovery rate; FDR; Genovese et al., 2002). $t$-values of significant activations of the highest activated voxels were given for the MNI-coordinates and were assigned to anatomical regions. All regions were detected with the "Automated Anatomical Labeling" software (AAL) (Tzourio-Mazoyer et al., 2002) or if already cytoarchitectonically mapped (primary motor cortex (BA 4a and p); primary somatosensory cortex (BA 1,2,3), primary auditory cortex (PAC 1.0, 1.1, 1.2), Broca's area and analogon (BA 44/45) and SII (POP 1,3 and 4; Morosan et al., 2001, Wernickes area) with maps based on cytoarchitectonical data with $50 \%$ probability (Eickhoff et al., 2005). The auditoryassociation area in the temporo-parietal lobe was selected after the highest activated voxels given by Hickok et al. (2003). The lateralization index (LI) was calculated with the LI-tool (Wilke and Schmithorst, 2006) by the following formula: (left-right)/ (left+right). Activation maps were projected on a T1-weighted anatomical image, which fits best to the MNI-space by using MRIcro software (http://www.sph.sc.edu/comd/rorden/mricro. html).

\section{Results}

\section{Rating of imagery}

Concentration $(7.57 \pm 1.73$ of 10$)$, vividness of imagined singing (7.15 \pm 2.04 of 10$)$, tempo (7.72 \pm 2.54 of 10$)$, rhythm $(7.56 \pm 2.35$ of 10$)$ and singing related movement $(6.13 \pm 2.13$ of 10) were rated moderate to high and did not differ significantly (Fig. 1C).

\section{EMG-measures}

ANOVA revealed a significant effect for condition (overt, imagined and baseline; $F(9,1)=48,45 ; p<0.001$ ) for the superficial EMG of musculus cricothyroideus. Post-hoc paired $t$-tests revealed no difference between baseline and imagined singing $(t(8)=0.52$; n.s.) whereas singing versus imagined singing $(t(9)=5.33$; $p<0.001)$ and singing versus baseline differed significantly $(t(9)=$ $5.28 ; p<0.001)$.

\section{fMRI-effects}

\section{Overt singing}

The results of the main effect for singing performance are plotted in Supplementary Table 1 and examples of activation sites are given in Fig. 2. Overt singing involved the primary sensorimotor cortex bilaterally (in the somatotopic representation of articulatory movements) but also secondary motor areas (SMA, right PMC), basal ganglia, the thalami, the cerebellar hemispheres and the vermis. Interestingly, medulla activation was found around the nuclei of the cerebral nerves V, IX, X, XII, associated with articulation and phonation. The primary auditory cortex (A1) and the surrounding belt area were active bilaterally during singing in comparable magnitude (lateralization index (LI) A1: 0.06). The auditory association area was active bilaterally (left: $t=4.91$, peak 


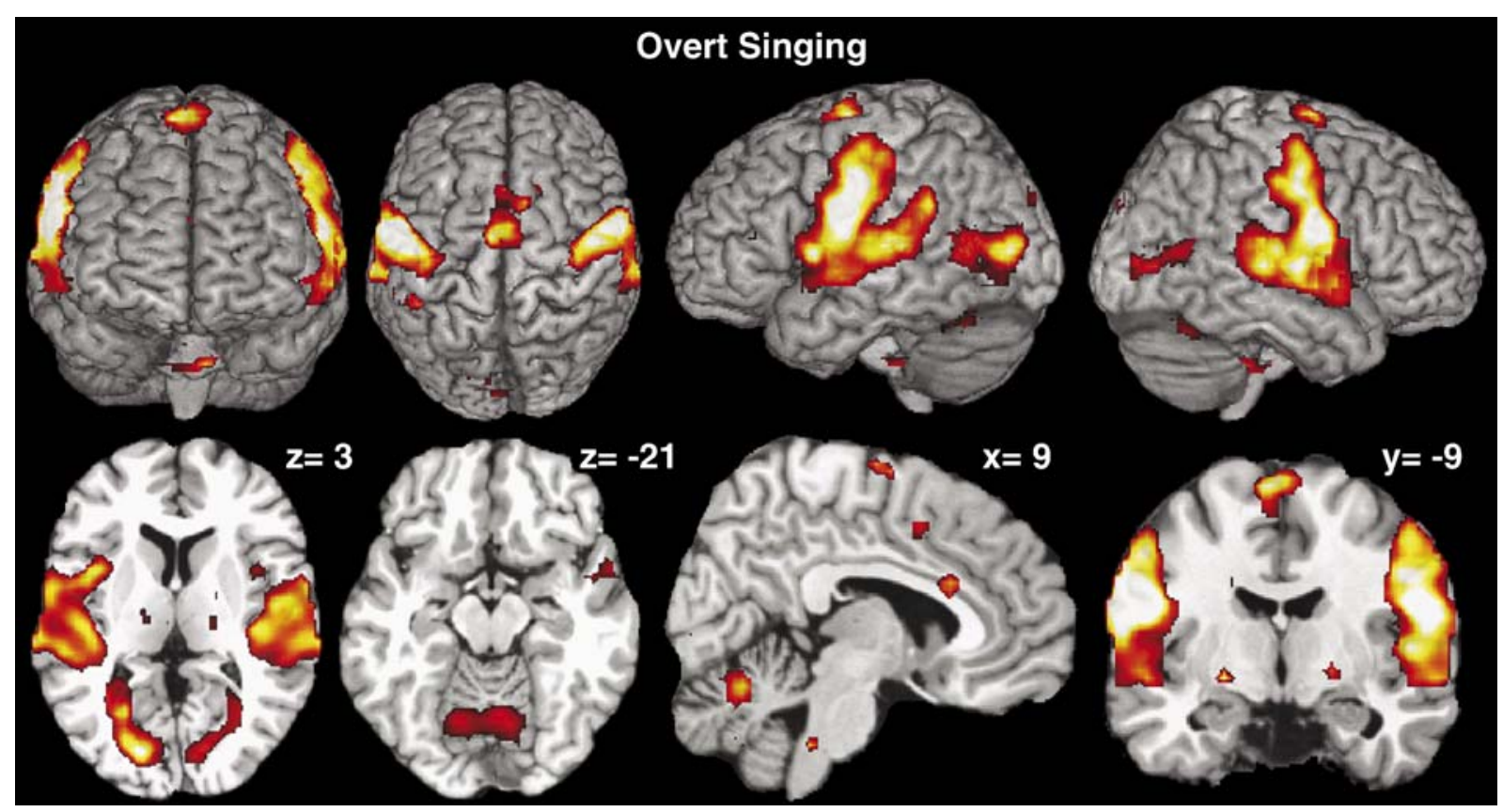

Fig. 2. Main effect 1: Overt singing; Activation maps were projected on Collin's reference brain, provided by MRIcro, which is most similar to the MNI-average brain. Bilateral sensorimotor cortex and cerebellum, bilateral auditory cortex, Broca's and Wernicke's area and their homologues, medulla, thalamus and ventral striatum but also ACC and insula were activated. Coordinates of cuts are given above each slice.

in $-51 ;-42 ; 21$; right $t=3.03,51 ;-36 ; 18)$. Both, Broca's and Wernicke's areas and their homologues were activated. No area (BA 44/45, S1, M1, SII, PMC, parietal) showed relevant lateralization $(\mathrm{LI}<0.05)$. Some areas related to emotional processing (anterior insula, ACC) showed significant activation.

\section{Imagined singing}

The results of the main effect for imagined singing performance are plotted in Supplementary Table 2 and examples of activation sites are given in Fig. 3. Imagined singing activated predominantly the fronto-parietal loop. This included secondary and tertiary motor

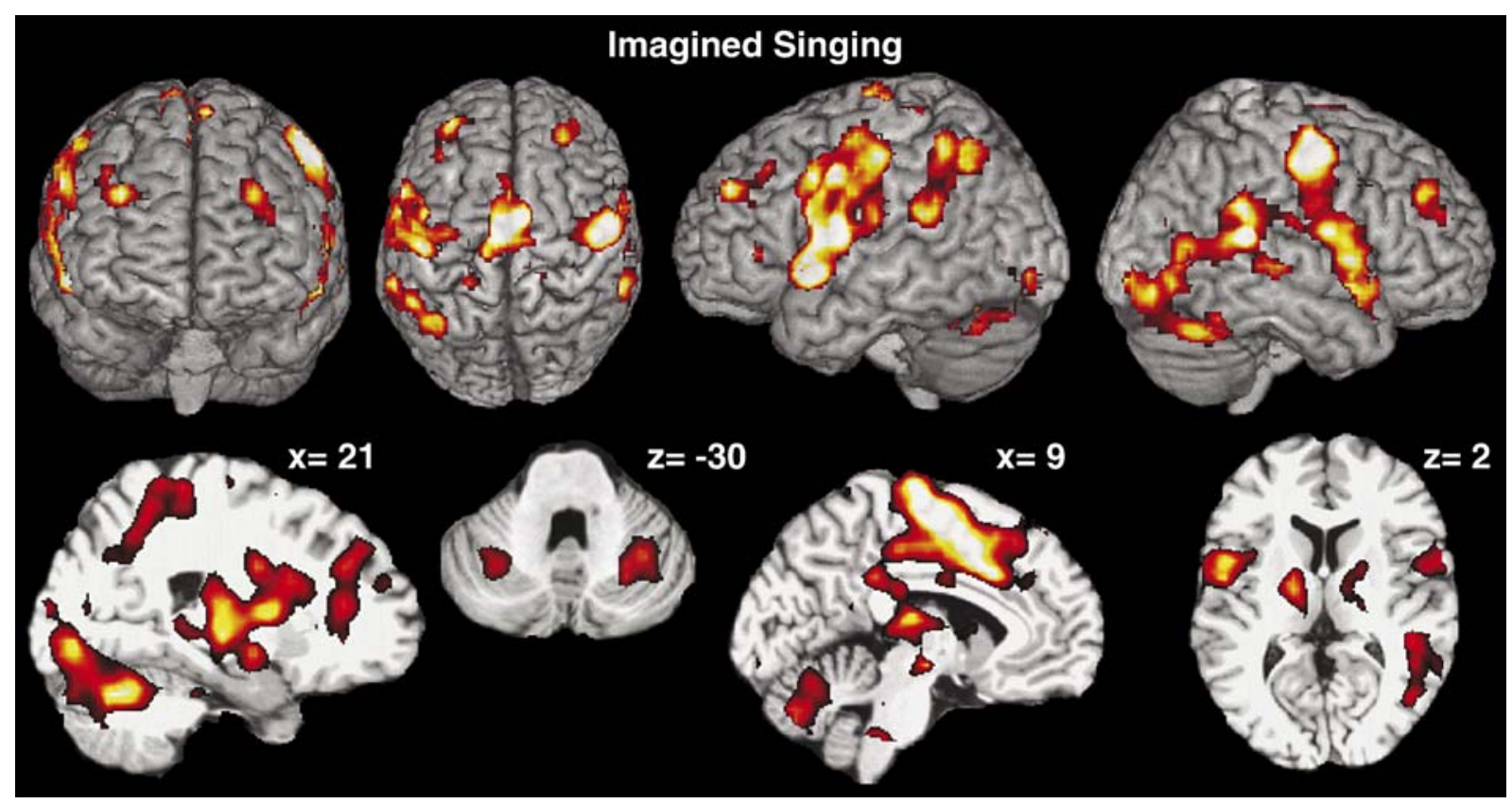

Fig. 3. Main effect 2: Mental rehearsal of singing involved increasingly typical imagery regions (SMA, PMC, parietal lobe, BA 44/45 bilaterally) as well as primary sensorimotor areas, the thalamus, the basal ganglia and more inferior regions of the cerebellum in both hemispheres. Areas processing emotions showed intense activation (ACC and bilateral insula, hippocampus, bilateral amygdala, ventrolateral prefrontal cortex). Bilateral A1 showed no significant activation. Coordinates of cuts are given above each slice. 
areas (supplementary motor area (SMA); premotor cortex (PMC)), Broca's area and its homologue (no lateralization; $\mathrm{LI}<0.11$ ) and the superior and inferior parietal lobe. Additionally, subcortical motor areas were involved (bilateral cerebellar hemisphere and vermis, bilateral putamen, pallidum and caudate nucleus). Interestingly, the primary motor (M1) and somatosensory cortex (S1) and the thalami were active bilaterally. Furthermore, the medulla was also active during imagery. No activation was found in the primary auditory cortex or in the auditory belt area but in the temporo-parietal lobe bilaterally (left: $t=4.90$, peak in -51 ; -42 ; 21 ; right $t=9.73,48 ;-39 ; 15)$. Several areas associated with emotional processing showed significant activation (anterior insula, bilateral amygdala, ACC, bilateral temporal pole, bilateral anterior hippocampus, $\mathrm{mPFC}$ ).

\section{Overt minus imagined singing}

The results of the difference in activation maps for the calculation overt minus imagined singing are plotted in Table 1 and examples of activation sites are given in Fig. 4A. Overt minus imagined singing revealed bilateral activation in the primary motor cortex, in the primary and secondary somatosensory cortex, bilateral superior temporal gyrus including primary auditory cortex. Subcortical motor areas (right cerebellar hemisphere, thalamus, medulla) showed also an increase during execution.

\section{Imagined minus overt singing}

The results of the difference in activation maps for the calculation imagined minus overt singing are plotted in Table 2 and examples of activation sites are given in Fig. 4B. Imagined minus overt singing showed increased activity in the SMA, the prefrontal cortex (PFC) and the inferior parietal lobe. Broca's and Wernicke's area and their homologues were stronger activated during the imagination task. Areas associated with emotional processing were also enhanced during imagined singing (ACC, ventrolateral and medial prefrontal cortex).

\section{Discussion}

In the present study, we report cerebral activation sites of professional singers during singing and imagined singing of an Italian aria. Using a sparse sampling technique, cerebral mapping of overt and imagined singing revealed a number of activation sites. These sites were subsumed in the following subgroups: those involved with the motor performance or the motor-concept; those involved in auditory control of the produced sound and in the audiomotor co-processing, those involved in working-memory processes (or involved in the recall of lyrics and musical aspects of the song respectively) and areas involved in emotional processing. These functional loops do partially overlap. Since our material contains both lyrics and melody this study will not contribute to the extensive discussion about overlapping or differentiated functional maps of language and music (e.g. Patel, 2003). Interestingly, most areas involved in motor processing were also activated during imagined singing. In contrast, most areas involved in auditory control during overt singing were absent during imagery of singing. Imagined singing showed increased activation in the fronto-parietal lobes but also in areas involved in emotional processing.

\section{Motor system}

\section{Cortex}

The cortical representation sites in the sensorimotor cortex comprised large areas centered in the somatotopic representation of the articulators and lip and tongue movements (Lotze et al., 2000a, b). No activity was seen in the supposed representation of the diaphragm and inspiration muscles in the area of the thoracic wall. Probably because deep inspirations were also performed in the baseline period and these activations might have been subtracted out. Activation in the primary motor (M1) and somatosensory cortex (S1) was significantly increased during overt singing in a pattern, similar to one recently reported for non-professional singers (Ozdemir et al., 2006). Interestingly, M1 and S1 were also present during imagined singing. Earlier studies on imagined performance in instrumentalists did not observe significant M1 and S1 activation (Langheim et al., 2002; Lotze et al., 2003). This could be a consequence of the increased statistical power of the present study which investigated more subjects - it has been reported that imagery involves $\mathrm{M} 1$ in about $30 \%$ of the intensity than executed performance does (Lotze et al., 1999; Porro et al., 1996). On the other hand, subtle movements of the articulators during scanning cannot not be fully excluded based on superficial EMG of baseline and imagined singing outside of the fMRI scanner or by controlling

Table 1

Overt minus imagined singing (FDR corrected: $p<0.05$ for the whole brain; only more than 5 voxel active per ROI are plotted; cytoarchitectural masks are indicated with $\mathrm{a}^{*}$ )

\begin{tabular}{|c|c|c|c|c|c|}
\hline Area & Cluster in mask & $t$-value & $x$ & $y$ & $z$ \\
\hline Left S1* (primary sensorymotor; BA $1,2,3$ ) & 34 & 6.18 & -57 & -12 & 33 \\
\hline Right $\mathrm{S} 1 *$ (primary sensorymotor; BA $1,2,3$ ) & 45 & 4.85 & 39 & -24 & 39 \\
\hline Left M1* (primary motor cortex; BA $4 \mathrm{a}+\mathrm{p}$ ) & 16 & 5.97 & -54 & -9 & 33 \\
\hline Right M1* (primary motor cortex; BA $4 \mathrm{a}+\mathrm{p}$ ) & 17 & 5.02 & 48 & -12 & 36 \\
\hline Left A1* (primary auditory cortex; BA 41) & 42 & 6.01 & -39 & -30 & 12 \\
\hline Right A1* (primary auditory cortex; BA 41) & 67 & 5.44 & 45 & -21 & 12 \\
\hline Left superior temporal gyrus (BA 22) & 336 & 5.66 & -45 & -21 & 3 \\
\hline Right superior temporal gyrus (BA 22) & 333 & 5.47 & 66 & -3 & -6 \\
\hline Left occipital lobe (BA 17, 18, 19) & 34 & 5.20 & -21 & -75 & 9 \\
\hline Left cerebellar hemisphere (H VII) & 16 & 5.02 & -9 & -42 & -24 \\
\hline Right cerebellar hemisphere (H VII) & 8 & 4.14 & 15 & -63 & -24 \\
\hline Left SII* (secondary sensory cortex; OP $1,3,4$ ) & 44 & 7.38 & -63 & -9 & 21 \\
\hline Right SII* (secondary sensory cortex; OP $1,3,4$ ) & 29 & 5.59 & 63 & -6 & 12 \\
\hline Medulla & 30 & 5.29 & 6 & -30 & -45 \\
\hline Thalamus & 5 & 4.41 & 18 & -24 & -3 \\
\hline
\end{tabular}




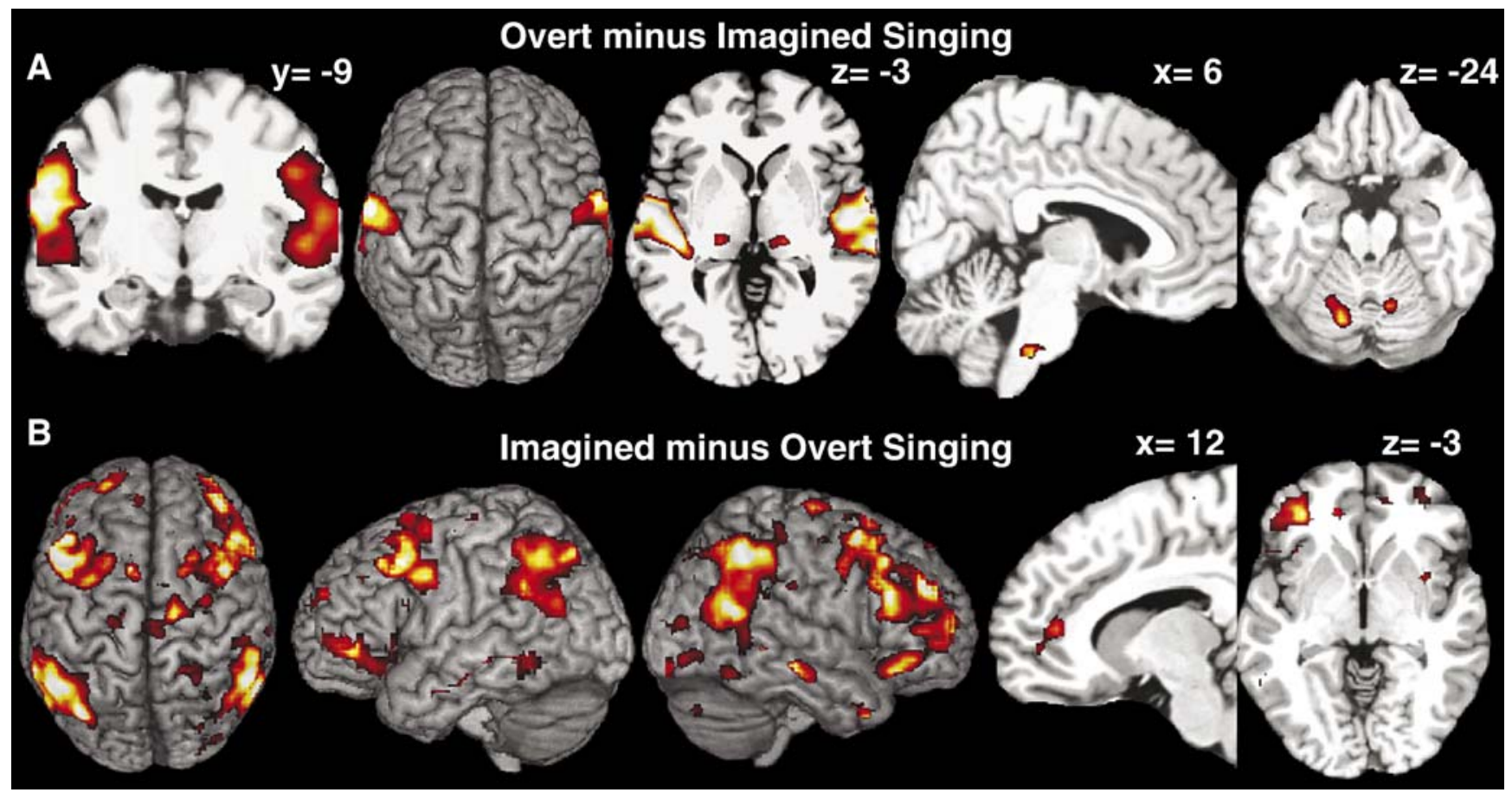

Fig. 4. (A) Overt singing showed higher activation in bilateral sensorimotor cortex in the somatotopic representation of the articulators, bilateral auditory cortex and other areas of the superior temporal gyrus, SII, superior cerebellar hemispheres, thalamus and medulla. (B) Mental rehearsal of singing showed higher activation in BA 6 (SMA and PMC), dorsal and ventrolateral prefrontal cortex, BA 44 left and 45 right, the parietal lobe and the ACC. Coordinates of cuts are given above each slice.

for sound production during the imagery-task in the scanner - an important difference to the feasible EMG-control of hand movements in instrumentalists during scanning. However, it has been previously reported that imagined singing (without EMG-control) may also involve the precentral gyrus (Wildgruber et al., 1996). Therefore, we assume that imagined singing might indeed differ to imagined instrumental performance with respect to the involvement of M1 and S1. This may be further supported by activation of the anterior insula during both, overt and imagined singing. While the anterior insula plays an important role in emotion processing (see discussion below), the left insula also seem to contribute to the actual coordination of muscles engaged in articulation and phonation (Ackerman and Riecker, 2004).

\section{Cerebellum}

The representation sites in the anterior cerebellar hemispheres mirror those of the cortical sites around the central sulcus. The cerebellum is preferentially involved in timing of complex movements with sensory feedback (Thach et al., 1992) and has been reported to serve additionally as an integrator of multisensory information from the cerebral cortex into a motor frame of reference (Bloedel et al., 1993). The spinocerebellum is also involved in sensorimotor tasks (Gao et al., 1996). Activation maps were larger than those reported for simple tongue and lip movements but were predominantly restricted to the area inferior to the fissura prima (Larsell lobule HVIa) (Grodd et al., 2001). Consistent with previous observations, imaging showed an

Table 2

Imagined minus overt singing (FDR corrected: $p<0.05$ for the whole brain; only more than 5 voxel active per ROI are plotted; cytoarchitectural masks are indicated with $\left.\mathrm{a}^{*}\right)$

\begin{tabular}{|c|c|c|c|c|c|}
\hline Area & Cluster in mask & $t$-value & $x$ & $y$ & $z$ \\
\hline SMA* (medial supplementary motor; BA 6) & 26 & 7.25 & -9 & 12 & 51 \\
\hline Right PFC (ant. med front gyrus; BA 9) & 5 & 5.70 & 42 & 45 & 33 \\
\hline Left ventrolateral prefrontal (BA 47) & 13 & 4.22 & -36 & 30 & -12 \\
\hline Right ventrolateral prefrontal (BA 47) & 10 & 4.76 & 42 & 39 & -9 \\
\hline Anterior cingulate cortex (ACC; BA 24) & 34 & 6.18 & 9 & 42 & 9 \\
\hline Inf-anterior cingulate gyrus & & 4.86 & -15 & 45 & -6 \\
\hline Left parietal inferior (BA 39, 40) & 156 & 6.79 & -48 & -57 & 48 \\
\hline Right parietal inferior (BA 39, 40) & 93 & 7.23 & 60 & -51 & 45 \\
\hline Left parietal superior (BA 5, 7) & 9 & 4.86 & -33 & -75 & 51 \\
\hline Right BA 45* (Brocca's analogon, BA 45) & 42 & 5.61 & 51 & 27 & 24 \\
\hline Left BA 44* (Brocca’s area, BA 44) & 6 & 4.35 & -50 & 9 & 42 \\
\hline Left angular gyrus (BA 40) & 110 & 6.19 & -39 & -69 & 45 \\
\hline Right angular gyrus (BA 40) & 77 & 5.12 & 57 & -63 & 24 \\
\hline
\end{tabular}


activation peak inferior and posterior Larsell's lobule HVII to areas involved in motor execution in the cerebellum (Lotze et al., 1999) but extended also anteriorly to HVIb. Cerebellar activity is highly correlated with the temporal sequencing of speech movement (Mathiak et al., 2002). The functional demands of singing may explain this activity. Vermis activation, not described in previous studies investigating singing, was present during overt singing. The vermis is involved in balancing of the body during gait (lesiondata: (Muley and Bushara, 2004); imaging-data: (Jahn et al., 2004)). For singing, only speculative interpretations of the function of the vermis can be provided - it may also be associated with the unnatural lying-position during classical singing in the scanner. It would be interesting in this context to investigate in a further study whether opera singers, who are often required to sing in unusual positions show increased vermis-activation when compared to, for example, concert singers.

\section{Basal ganglia}

Parts of the dorsal basal ganglia (putamen and pallidum) were activated during singing. This activation is likely to be associated with the motor loop (Alexander and Crutcher, 1990) and less so with the sensory-attentional loop (Liu et al., 1999). Here the basal ganglia may be involved in the modulation of the voice, comparable to the modulation of smooth movement performance (Brooks, 1995).

Interestingly, the basal ganglia were also active during imagined singing. Comparison between overt singing and imagined singing revealed no differences. Basal ganglia activation may indicate an associative connection during overt and imagined singing between the dorsolateral prefrontal and orbito-frontal cortex via the nucleus caudatus pointing to working memory activation (dorsolateral PFC) and perhaps to an anticipatory finetuning of text and melody (ventrolateral PFC). The basal ganglia activation also involves the limbic-emotional loop predominantly connecting the ventral striatum with the ACC (Alexander and Crutcher, 1990). In contrast to other studies on musical perception (Blood and Zatorre, 2001; Menon and Levitin, 2005) we did not observe any activation in the nucleus accumbens located in the ventral striatum. The reason for this is unclear; both the unusual situation for classical singers to overtly singing (or mentally singing) in the scanner and the strict regime of the task may have decreased the pleasure of this aria.

\section{Medulla}

We observed circumscribed activation in the superior medulla in a region where cranial nerves VII, IX, X and XII are relayed to articulation, vocalization and phonation related movements. This activation is most likely not elicited by movement artifacts, resulting in articulation dependent cerebral fluid pulsation since activation maxima were located distinct from the border of the spinal fluid and the brain stem (see Figs. 2 and 4). Patients with lesions in the superior medulla demonstrate drastic impairments in articulation, and swallowing (Vuilleumier et al., 1995). The activation in the brainstem was significantly increased for overt minus imagined singing pointing to the executive function of this activation site.

\section{Secondary motor areas (BA 6)}

The supplementary motor area (SMA) and the medial cingulate cortex were comparably active during both overt and imagined singing. Both areas have previously been described to be involved in overt vocalization (Perry et al., 1999). Together with the premotor cortex (PMC) these areas seem to be critical for the planning, timing and ideation of the movement and the motor imagery (for an overview see: Lotze and Halsband, 2006). It is possible that the access to motor programs during mental rehearsal is realized through functional activation of BA 6 , which has also shown to be involved in kinesthetic imagery tasks (Gerardin et al., 2000; Stephan et al., 1995).

\section{Areas involved in auditory control}

During overt singing, we observed bilateral activation of the primary auditory cortex (A1) and the auditory belt area with comparable intensity. Recent functional imaging studies suggest a relative left-hemispheric specialization for rapid temporal and rhythm processing (Boemio et al., 2005; Overy et al., 2004; Zatorre and Belin, 2001) whereas right auditory cortex shows a stronger sensitivity for spectral and melody processing (Overy et al., 2004; Zatorre and Belin, 2001) and for processing of auditory information with slower temporal resolution (Boemio et al., 2005). With regard to lateralization effects of primary auditory cortex, simple humming without language production showed A1 activation only in the right hemisphere (Perry et al., 1999) but pitch memory has also been associated with increases in the left Heschl's gyrus (Gaab et al., 2006). The ambiguous role of A1 lateralization in melody perception tasks may be mediated by the listening style (Evers et al., 1999), e.g. spectral pitch listeners possessed a pronounced rightward activity in the lateral Heschl's gyrus when compared to fundamental pitch listeners (Schneider et al., 2005). The Italian aria used in our study was comprised of text, rhythm and melody. Thus, the bilateral activation of A1 with comparable magnitude is not surprising. The activation of the auditory cortex found in our study was similar to the one reported by Ozdemir and colleagues (2006) for non-professional singers, who also found bilateral activation in the middle section of the superior temporal lobe for overt singing as well as for overt speaking when compared to silence, suggesting a bihemispheric activation for both tasks. In their study, only in the singing, more than speaking contrast, A1 activation was more pronounced on the right than on the left. Callan et al. (2006) compared Japanese singing versus speech production and found an increased activation for singing in the right planum temporale. Since speech was highly lateralized to the left in their study, bilateral planum temporale activation during singing resulted in increased right hemispheric activity after contrasting singing minus speech. This is in concordance with our findings of bilateral planum temporale activation during singing.

During the imagery task activation of A1 (Morosan et al., 2001) was completely absent (see Fig. 3). This result is in line with several observations on sound and music imagery, which found activity only in the secondary auditory cortex but not in A1 (Ducreux et al., 2003; Halpern and Zatorre, 1999; Kraemer et al., 2005; Yoo et al., 2001; Zatorre and Halpern, 2005). It is interesting in this regard that our subjects rated the vividness of imagined singing as high and reported no problems in attention during the imagery task. Additionally, the sparse sampling technique avoided distraction by the scanner noise (Mazard et al., 2002). Vividness of imagery has previously been shown to correlate high with psychophysiological responses during imagery (Lang, 1979). Yet we did not assess to what extent our subjects experienced the imagined aria auditorily or kinesthetically. Two earlier studies that investigated imagined performance in instrumentalists did also not observe A1 activation during imagery 
(Langheim et al., 2002; Lotze et al., 2003) although the rating of imagined melody was high (Lotze et al., 2003). Conversely, when professional and amateur violinists were tapping an imagined and well-known piece of music without auditory feedback, activations in the primary auditory cortex were found, especially in the professional group (Lotze et al., 2003). This finding may represent a tight interconnection between motor action, sensory perception and auditory control in musicians (Bangert et al., 2001; D'Ausilio et al., 2006). Comparable cross-modal interactions in singers could be perturbed by the lack of activity in the somatosensory and motor modality. However, that assumption is contradicted by the activity of M1 and S1 during imagined singing in our study.

An auditory association area in the left hemisphere was reported to be responsible for the control of spoken and listened words (Hickok et al., 2003). We also observed activity around the peak of this area in the temporo-parietal lobe during both overt and imagined singing, although it was bilaterally expressed. It is possible that auditory association for leading the melody during both singing and imagined singing may be represented in this area.

\section{Speech and song processing}

We observed no relevant lateralization during both singing and mental singing in Broca's area. Bilateral activation in comparable magnitude may be related to the combination of melody and lyrics in the Italian aria. Compared to simple humming, which showed right lateralized activity (Perry et al., 1999), the singing of an aria involved also linguistic, tempo and rhythm processing previously shown to be lateralized to the left (Tramo, 2001). In a very recent paper Lahav et al. (2007) compared listening to untrained and trained musical sequences. Interestingly, Brocca's area and its analogon were increasingly active during listening to a trained piece compared to listening to the same piece before training. The authors interpreted these findings as a multifunctional role of this area in action listening but also as another indication of its role for sensorimotor integration (Binkofski et al., 2000). In the light of this study, our findings of bilateral activation in the inferior frontal gyrus present during both overt and imagined singing might not necessarily be related to the recall and internal representation of lyrics but might point to the recall of trained motor processes or sensorimotor interactions.

Increased processing of memory for pitch was reported to be related to activation in BA6, 44, 45, and BA 40 and 7 (Koelsch and Siebel, 2005) - areas that showed increased activation during the imagery task in our study. Together with additional mobilization for mental rehearsal around BA 9 (Zhang et al., 2003) this increase for mental rehearsal may suggest that it is less automatized than overt singing. If the auditory feedback is missing, increased resources may be needed to keep track, which may lead to an increased working memory demand in the frontal and parietal lobes. The inferior frontal cortex seem to play a role in the processing of musical structure and syntax (Tillmann et al., 2006) and has been attributed to emotional intonation (Wildgruber et al., 2005) as well as to motor preparation for vocal production (Ozdemir et al., 2006). Auditory imagery of familiar melodies and inner speech has also shown to involve the inferior frontal gyrus together with SMA and auditory association areas in the superior temporal gyrus (Halpern and Zatorre, 1999; Shergill et al., 2001). All these areas where observed during imagined singing in our study supporting the notion that the frontal cortex may be involved in auditory imagery processes (Zatorre and Halpern, 2005).
Parieto-temporal association areas for control of auditory stimulation are located near or within Wernicke's area and its homologue. Its involvement in auditory imagery has been demonstrated before (Halpern and Zatorre, 1999; Shergill et al., 2001). We found increased inferior parietal cortex activation bilaterally during both tasks, which could reflect activation of a store for phonetic and intonational acoustic information contributing to the working memory system (Wildgruber et al., 2005; Zatorre, 2001; Zatorre et al., 1994).

The superior parietal lobe (BA 7) also showed increased activation during imagined singing. This area has been reported to be activated during imagery involving complex trajectories of movements (Wolbers et al., 2003). The superior parietal lobe is closely connected with the posterior SMA but also with the PMC (Rizzolatti and Arbib, 1998). Spatial trajectories of the movement may be transformed in corresponding motor programs processed and stored in the superior parietal lobe. Patients with parietal lesions were found to have problems with tasks that involve imagined movements (Sirigu et al., 1996). Thus, the parietal lobe seems to be crucial for mental rehearsal. This may be especially true for musicians since more inferior parts of the parieto-temporal lobe found during imagery could be essential for the auditory processing of the piece mentally rehearsed.

Activation in the occipital lobe, present during both overt and imagined singing, was enhanced during overt singing. One could argue that overt singing needs a closer attentive control of the symbolic instructions, which indicated onset and end of a performance period. Nevertheless, Perry et al. (1999) reported occipital activation during humming although his subjects had their eyes closed. They concluded that visual imagery might account for this activation.

\section{Emotional processing}

The overt singing task activated only the anterior cingulate cortex (ACC; for differentiation see: (Bush et al., 2000) and the insula. The ACC is involved in the recall of emotions (Phan et al., 2004) - a capability which might be important for both overt and mental performance.

We observed bilateral insula activation during overt and imagined singing, an area that has been termed "limbic sensory cortex" and that is associated with emotional states, emotional recall/imagery and emotional tasks with cognitive demand (Phan et al., 2002). Insula activation has also been reported for the experience of "chills" during the perception of pleasurable music (Blood and Zatorre, 2001). Whereas the anterior insula is related to emotional valence, the dorsal part of this structure is more active during cognitive tasks (for a meta-analysis see Wager and Barrett, 2004). Anterior insula activation seems to reflect the intensity dimension of an emotion (Anders et al., 2004).

Imagined singing involved additional activation in areas related to emotional processing such as the medial prefrontal cortex (mPFC), the bilateral ventrolateral prefrontal cortex (VLPFC; also called orbitofrontal lobe; BA 47), bilateral temporal poles and bilateral amygdala. The temporal poles are involved in conscious self-regulation of emotional responses (Beauregard et al., 2001; Lane, 2000). The amygdala is known to be predominantly involved in more passive avoidance or approach tasks (Morris et al., 1999a,b). This is consistent with the fact that the amygdala was not active during overt singing. Although amygdala activation has been reported for the perception of unpleasant musical material (Blood et 
al., 1999; Koelsch, 2005; Koelsch et al., 2005) its activation is not specific for negative emotions.

Other areas such as the mPFC, the VLPFC - active during imagined singing in our study - have also been related to unpleasant musical stimuli (Blood et al., 1999), but results from meta-analyses on studies investigating visually presented emotional material did not find area specificity for positively or negatively rated stimuli (Murphy et al., 2003; Phan et al., 2002). Instead, the mPFC may play a "general" role in emotional processing for appraisal/evaluation, experience and response and can be related to self-referential processing about one's own emotional experience (Phan et al., 2004). VLPFC-activation in BA 47 is associated with prosody perception (Wildgruber et al., 2005) and visually presented expressive gestures (Lotze et al., 2006). Lesions in this area result in impaired recognition of vocal expressions (Hornak et al., 2003). Significantly increased activation during imagined singing compared to overt singing was only observed in the ACC and the VLPFC. Therefore, we believe that enhanced activation in these areas may reflect an increased emotional recall during the task.

\section{Conclusion}

Several studies have proven the value of music imagery to improve various aspects of overt performance (Highben and Palmer, 2004; Humphreys, 1986; Lacourse et al., 2005; Pascual-Leone, 2003; Yaguez et al., 1998). By comparing overt and imagined singing of an Italian aria we showed a broad range of activation in partly overlapping cortical and subcortical areas. While overt singing activated predominantly areas processing complex motor sequences and sensory feedback/control, most of these areas related to motor processing where also active during imagery, a finding that may explain the significance of imagined rehearsal for motor performances. In line with previous research, we found no involvement of primary auditory cortex during imagery whereas secondary auditory areas showed activation. Imagined singing activated a large fronto-parietal network, indicating increased involvement of working memory processes during mental imagery. This activation possibly indicates that imagined singing is less automatized than overt singing, even though subjects reported frequent use of imagined rehearsal. We speculate that the associative networks activated during imagery are more complex, more variable and more adjusted to the individuals' personal training history. Imagery "frees" us from the chains of external perceptual cues. Areas processing emotions showed also enhanced activation during imagined singing, which may reflect increased emotional recall during this task. A future study will concentrate on correlates of singing related to the degree of professionalism with activation intensities in the functional regions described in this study.

\section{Acknowledgments}

We want to thank the Staatliche Hochschule für Musik und Darstellende Kunst Stuttgart and the Staatsoper Stuttgart for their support. This study was supported by the Deutsche Forschungsgemeinschaft (DFG) and the Andrea von Braun Stiftung, München.

\section{Appendix A. Supplementary data}

Supplementary data associated with this article can be found, in the online version, at doi:10.1016/j.neuroimage.2007.02.053.

\section{References}

Ackerman, H., Riecker, A., 2004. The contribution of the insula to motor aspects of speech production: a review and a hypothesis. Brain Lang. 89, 320-328.

Alexander, G.E., Crutcher, M.D., 1990. Functional architecture of basal ganglia circuits: neural substrates of parallel processing. Trends Neurosci. 13, 266-271.

Anders, S., Lotze, M., Erb, M., Grodd, W., Birbaumer, N., 2004. Brain activity underlying emotional valence and arousal: a response-related fMRI study. Hum. Brain Mapp. 23, 200-209.

Bangert, M., Haeusler, U., Altenmuller, E., 2001. On practice: how the brain connects piano keys and piano sounds. Ann. N. Y. Acad. Sci. 930, 425-428.

Beauregard, M., Levesque, J., Bourgouin, P., 2001. Neural correlates of conscious self-regulation of emotion. The Journal of neuroscience 21, RC165.

Binkofski, F., Amunts, K., Stephan, K.M., Posse, S., Schormann, T., Freund, H.J., Zilles, K., Seitz, R.J., 2000. Broca's region subserves imagery of motion: a combined cytoarchitectonic and fMRI study. Hum. Brain Mapp. 11, 273-285.

Bloedel, J.R., Bracha, V., Larson, P.S., 1993. Real time operations of the cerebellar cortex. Can. J. Neurol. Sci. 20 (Suppl. 3), S7-S18.

Blood, A.J., Zatorre, R.J., 2001. Intensely pleasurable responses to music correlate with activity in brain regions implicated in reward and emotion. Proc. Natl. Acad. Sci. U. S. A. 98, 11818-11823.

Blood, A.J., Zatorre, R.J., Bermudez, P., Evans, A.C., 1999. Emotional responses to pleasant and unpleasant music correlate with activity in paralimbic brain regions. Nat. Neurosci. 2, 382-387.

Boemio, A., Fromm, S., Poeppel, D., 2005. Hierarchical and asymmetric temporal sensitivity in human auditory cortices. Nat. Neurosci. 8, 389-395.

Brooks, D.J., 1995. The role of the basal ganglia in motor control: contributions from PET. J. Neurol. Sci. 128, 1-13.

Brown, S., 2000. The "musilanguage" model of music evolution. In: Wallin, N.L., Merker, B., Brown, S. (Eds.), The Origins of Music. MIT Press, Cambridge, MA, pp. 271-300.

Bunzeck, N., Wuestenberg, T., Lutz, K., Heinze, H.J., Jancke, L., 2005. Scanning silence: mental imagery of complex sounds. NeuroImage 26, 1119-1127.

Bush, G., Luu, P., Posner, M.I., 2000. Cognitive and emotional influences in anterior cingulate cortex. Trends Cogn. Sci. 4, 215-222.

Caldara, R., Deiber, M.P., Andrey, C., Michel, C.M., Thut, G., Hauert, C.A., 2004. Actual and mental motor preparation and execution: a spatiotemporal ERP study. Exp. Brain Res. 159, 389-399.

Callan, D.E., Tsytsarev, V., Hanakawa, T., Callan, A.M., Katsuhara, M., Fukuyama, H., Turner, R., 2006. Song and speech: brain regions involved with perception and covert production. NeuroImage 1, 1327-1342.

D’Ausilio, A., Altenmüller, E., Olivetti Belardinelli, M., Lotze, M., 2006. Cross modal plasticity of the motor cortex while listening to a rehearsed musical piece. Eur. J. Neurosci. 24, 955-958.

Ducreux, D., Marsot-Dupuch, K., Lasjaunias, P., Oppenheim, C., Fredy, D., 2003. Lyrical and musical auditive mental imagery in functional MRI. J. Neuroradiol. 30, 18-24.

Eickhoff, S.B., Stephan, K.E., Mohlberg, H., Grefkes, C., Fink, G.R., Amunts, K., Zilles, K., 2005. A new SPM toolbox for combining probabilistic cytoarchitectonic maps and functional imaging data. NeuroImage 25, 1325-1335.

Evers, S., Dannert, J., Rodding, D., Rotter, G., Ringelstein, E.B., 1999. The cerebral haemodynamics of music perception. A transcranial Doppler sonography study. Brain 122 (Pt. 1), 75-85.

Gaab, N., Gaser, C., Zaehle, T., Jaencke, L., Schlaug, G., 2003. Functional anatomy of pitch memory — an fMRI study with sparse temporal sampling. NeuroImage 19, 1417-1426.

Gaab, N., Gaser, C., Schlaug, G., 2006. Improvement-related functional plasticity following pitch memory training. NeuroImage 31, 255-263. 
Gao, J.H., Parsons, L.M., Bower, J.M., Xiong, J., Li, J., Fox, P.T., 1996. Cerebellum implicated in sensory acquisition and discrimination rather than motor control. Science 272, 545-547.

Genovese, C.R., Lazar, N.A., Nichols, T., 2002. Thresholding of statistical maps in functional neuroimaging using the false discovery rate. Neuroimage 15, 870-878.

Gerardin, E., Sirigu, A., Lehericy, S., Poline, J.B., Gaymard, B., Marsault, C., Agid, Y., Le Bihan, D., 2000. Partially overlapping neural networks for real and imagined hand movements. Cereb. Cortex 10, 1093-1104.

Gerloff, C., Corwell, B., Chen, R., Hallett, M., Cohen, L.G., 1998. The role of the human motor cortex in the control of complex and simple finger movement sequences. Brain 121 (Pt. 9), 1695-1709.

Gieseking, W., Leimer, K., 1972. Piano Technique. Dover Publications Inc.

Gracco, V.L., Tremblay, P., Pike, B., 2005. Imaging speech production using fMRI. NeuroImage 26, 294-301.

Grodd, W., Hulsmann, E., Lotze, M., Wildgruber, D., Erb, M., 2001. Sensorimotor mapping of the human cerebellum: fMRI evidence of somatotopic organization. Hum. Brain Mapp. 13, 55-73.

Halpern, A.R., Zatorre, R.J., 1999. When that tune runs through your head: a PET investigation of auditory imagery for familiar melodies. Cereb. Cortex 9, 697-704.

Halpern, A.R., Zatorre, R.J., Bouffard, M., Johnson, J.A., 2004. Behavioral and neural correlates of perceived and imagined musical timbre. Neuropsychologia 42, 1281-1292.

Hickok, G., Buchsbaum, B., Humphries, C., Muftuler, T., 2003. Auditorymotor interaction revealed by fMRI: speech, music, and working memory in area Spt. J. Cogn. Neurosci. 15, 673-682.

Highben, Z., Palmer, C., 2004. Effects of auditory and motor mental practice in memorized piano performance. Bull. Counc. Res. Music Educ. 159, $58-65$

Hornak, J., Bramham, J., Rolls, E.T., Morris, R.G., O’Doherty, J., Bullock, P.R., Polkey, C.E., 2003. Changes in emotion after circumscribed surgical lesions of the orbitofrontal and cingulate cortices. Brain 126, $1691-1712$

Humphreys, J.T., 1986. Measurement, prediction, and training of harmonic audiation and performance skills. J. Res. Music Educ. 34, 192-199.

Hunter, M.D., Eickhoff, S.B., Miller, T.W., Farrow, T.F., Wilkinson, I.D., Woodruff, P.W., 2006. Neural activity in speech-sensitive auditory cortex during silence. Proc. Natl. Acad. Sci. U. S. A. 103, 189-194.

Jackson, P.L., Lafleur, M.F., Malouin, F., Richards, C., Doyon, J., 2001. Potential role of mental practice using motor imagery in neurologic rehabilitation. Arch. Phys. Med. Rehabil. 82, 1133-1141.

Jahn, K., Deutschlander, A., Stephan, T., Strupp, M., Wiesmann, M., Brandt, T., 2004. Brain activation patterns during imagined stance and locomotion in functional magnetic resonance imaging. NeuroImage $22,1722-1731$

Koelsch, S., 2005. Investigating emotion with music: neuroscientific approaches. Ann. N. Y. Acad. Sci. 1060, 412-418.

Koelsch, S., Siebel, W.A., 2005. Towards a neural basis of music perception. Trends Cogn. Sci. 9, 578-584.

Koelsch, S., Fritz, T., DY, V.C., Muller, K., Friederici, A.D., 2005. Investigating emotion with music: an fMRI study. Hum. Brain Mapp. 27, 239-250.

Kosslyn, S.M., Thompson, W.L., 2003. When is early visual cortex activated during visual mental imagery? Psychol. Bull. 129, 723-746.

Kraemer, D.J., Macrae, C.N., Green, A.E., Kelley, W.M., 2005. Musical imagery: sound of silence activates auditory cortex. Nature 434, 158

Kuhtz-Buschbeck, J.P., Mahnkopf, C., Holzknecht, C., Siebner, H., Ulmer, S., Jansen, O., 2003. Effector-independent representations of simple and complex imagined finger movements: a combined fMRI and TMS study. Eur. J. Neurosci. 18, 3375-3387.

Lacourse, M.G., Orr, E.L., Cramer, S.C., Cohen, M.J., 2005. Brain activation during execution and motor imagery of novel and skilled sequential hand movements. NeuroImage 27, 505-519.

Lahav, A., Saltzman, E., Schlaug, G., 2007. Action representation of sound: audiomotor recognition network while listening to newly acquired actions. J. Neurosci. 27, 308-314.
Lane, R.D., 2000. Neural correlates of conscious emotional experience. In: Lane, R.D., Nadel, L. (Eds.), Cognitive Neuroscience of Emotion. Oxford UP, New York, pp. 345-370.

Lang, P.J., 1979. Presidential address, 1978. A bio-informational theory of emotional imagery. Psychophysiology 16, 495-512.

Langheim, F.J., Callicott, J.H., Mattay, V.S., Duyn, J.H., Weinberger, D.R., 2002. Cortical systems associated with covert music rehearsal. NeuroImage 16, 901-908.

Liu, Y., Gao, J.H., Liotti, M., Pu, Y., Fox, P.T., 1999. Temporal dissociation of parallel processing in the human subcortical outputs. Nature 400, 364-367.

Lotze, M., Halsband, U., 2006. Motor imagery. J. Physiol. (Paris) 99, 386-395.

Lotze, M., Montoya, P., Erb, M., Hulsmann, E., Flor, H., Klose, U., Birbaumer, N., Grodd, W., 1999. Activation of cortical and cerebellar motor areas during executed and imagined hand movements: an fMRI study. J. Cogn. Neurosci. 11, 491-501.

Lotze, M., Erb, M., Flor, H., Huelsmann, E., Godde, B., Grodd, W., 2000a. fMRI evaluation of somatotopic representation in human primary motor cortex. NeuroImage 11, 473-481.

Lotze, M., Seggewies, G., Erb, M., Grodd, W., Birbaumer, N., 2000b. The representation of articulation in the primary sensorimotor cortex. NeuroReport 11, 2985-2989.

Lotze, M., Scheler, G., Tan, H.R., Braun, C., Birbaumer, N., 2003. The musician's brain: functional imaging of amateurs and professionals during performance and imagery. NeuroImage 20, 1817-1829.

Lotze, M., Heymans, U., Birbaumer, N., Veit, R., Erb, M., Flor, H., Halsband, U., 2006. Differential cerebral activation during observation of expressive gestures and motor acts. Neuropsychologia 44, $1787-1795$

Mathiak, K., Hertrich, I., Grodd, W., Ackermann, H., 2002. Cerebellum and speech perception: a functional magnetic resonance imaging study. J. Cogn. Neurosci. 14, 902-912.

Mazard, A., Mazoyer, B., Etard, O., Tzourio-Mazoyer, N., Kosslyn, S.M., Mellet, E., 2002. Impact of fMRI acoustic noise on the functional anatomy of visual mental imagery. J. Cogn. Neurosci. 14, 172-186.

Menon, V., Levitin, D.J., 2005. The rewards of music listening: response and physiological connectivity of the mesolimbic system. NeuroImage 28 , $175-184$.

Molino, J., 2000. Toward an evolutionary theory of music and language. In: Wallin, N.L., Merker, B., Brown, S. (Eds.), The Origins of Music. MIT Press, Cambridge, MA.

Morosan, P., Rademacher, J., Schleicher, A., Amunts, K., Schormann, T., Zilles, K., 2001. Human primary auditory cortex: cytoarchitectonic subdivisions and mapping into a spatial reference system. NeuroImage $13,684-701$

Morris, J.S., Ohman, A., Dolan, R.J., 1999a. A subcortical pathway to the right amygdala mediating "unseen" fear. Proc. Natl. Acad. Sci. U. S. A. $96,1680-1685$.

Morris, J.S., Scott, S.K., Dolan, R.J., 1999b. Saying it with feeling: neural responses to emotional vocalizations. Neuropsychologia 37, 1155-1163.

Muley, S.A., Bushara, K.O., 2004. Isolated gait ataxia due to cerebellar vermis infarct. Arch. Neurol. 61, 1461

Murphy, F.C., Nimmo-Smith, I., Lawrence, A.D., 2003. Functional neuroanatomy of emotions: a meta-analysis. Cogn. Affect. Behav. Neurosci. 3, 207-233.

Natke, U., Donath, T.M., Kalveram, K.T., 2003. Control of voice fundamental frequency in speaking versus singing. J. Acoust. Soc. Am. 113, 1587-1593.

Overy, K., Norton, A., Cronin, K., Gaab, N., Alsop, D., Winner, E., Schlaug, G., 2004. Differential lateralization for melody versus rhythm is already present in young children. NeuroReport 15, 1723-1726.

Ozdemir, E., Norton, A., Schlaug, G., 2006. Shared and distinct neural correlates of singing and speaking. NeuroImage 33, 628-635.

Pascual-Leone, A., 2003. The brain that makes music and is changed by it. In: Peretz, I., Zatorre, R.J. (Eds.), The Cognitive Neuroscience of Music. Oxford Univ. Press, Oxford, pp. 396-412. 
Patel, A.D., 2003. Language, music, syntax and the brain. Nat. Neurosci. 6, 674-681.

Perry, D.W., Zatorre, R.J., Petrides, M., Alivisatos, B., Meyer, E., Evans, A. C., 1999. Localization of cerebral activity during simple singing. NeuroReport 10, 3979-3984.

Phan, K.L., Wager, T., Taylor, S.F., Liberzon, I., 2002. Functional neuroanatomy of emotion: a meta-analysis of emotion activation studies in PET and fMRI. NeuroImage 16, 331-348.

Phan, K.L., Wager, T.D., Taylor, S.F., Liberzon, I., 2004. Functional neuroimaging studies of human emotions. CNS Spectr. 9, 258-266.

Porro, C.A., Francescato, M.P., Cettolo, V., Diamond, M.E., Baraldi, P., Zuiani, C., Bazzocchi, M., di Prampero, P.E., 1996. Primary motor and sensory cortex activation during motor performance and motor imagery: a functional magnetic resonance imaging study. J. Neurosci. 16, 7688-7698.

Riecker, A., Ackermann, H., Wildgruber, D., Dogil, G., Grodd, W., 2000. Opposite hemispheric lateralization effects during speaking and singing at motor cortex, insula and cerebellum. NeuroReport 11, 1997-2000.

Rizzolatti, G., Arbib, M.A., 1998. Language within our grasp. Trends Neurosci. 21, 188-194.

Sabbah, P., Simond, G., Levrier, O., Habib, M., Trabaud, V., Murayama, N., Mazoyer, B.M., Briant, J.F., Raybaud, C., Salamon, G., 1995. Functional magnetic resonance imaging at $1.5 \mathrm{~T}$ during sensorimotor and cognitive task. Eur. Neurol. 35, 131-136.

Schneider, P., Sluming, V., Roberts, N., Scherg, M., Goebel, R., Specht, H.J., Dosch, H.G., Bleeck, S., Stippich, C., Rupp, A., 2005. Structural and functional asymmetry of lateral Heschl's gyrus reflects pitch perception preference. Nat. Neurosci. 8 (9), 1241-1247.

Schonberg, H.C., 1987. Great Pianists. Simon \& Schuster, New York.

Shergill, S.S., Bullmore, E., Simmons, A., Murray, R., McGuire, P., 2000. Functional anatomy of auditory verbal imagery in schizophrenic patients with auditory hallucinations. Am. J. Psychiatr. 157, 1691-1693.

Shergill, S.S., Bullmore, E.T., Brammer, M.J., Williams, S.C., Murray, R.M., McGuire, P.K., 2001. A functional study of auditory verbal imagery. Psychol. Med. 31, 241-253.

Sirigu, A., Duhamel, J.R., Cohen, L., Pillon, B., Dubois, B., Agid, Y., 1996. The mental representation of hand movements after parietal cortex damage. Science 273, 1564-1568.

Soltysik, D.A., Hyde, J.S., 2006. Strategies for block-design fMRI experiments during task-related motion of structures of the oral cavity. NeuroImage 29, 1260-1271.

Stephan, K.M., Fink, G.R., Passingham, R.E., Silbersweig, D., CeballosBaumann, A.O., Frith, C.D., Frackowiak, R.S., 1995. Functional anatomy of the mental representation of upper extremity movements in healthy subjects. J. Neurophysiol. 73, 373-386.

Thach, W.T., Goodkin, H.P., Keating, J.G., 1992. The cerebellum and the adaptive coordination of movement. Annu. Rev. Neurosci. 15, 403-442.

Tillmann, B., Koelsch, S., Escoffier, N., Bigand, E., Lalitte, P., Friederici, A.D., von Cramon, D.Y., 2006. Cognitive priming in sung and instrumental music: activation of inferior frontal cortex. NeuroImage $31,1771-1782$
Tramo, M.J., 2001. Biology and music. Music of the hemispheres. Science 291, 54-56.

Tzourio-Mazoyer, N., Landeau, B., Papathanassiou, D., Crivello, F., Etard, O. Delcroix, N., Mazoyer, B., Joliot, M., 2002. Automated anatomical labeling of activations in SPM using a macroscopic anatomical parcellation of the MNI MRI single-subject brain. NeuroImage 15, 273-289.

Voisin, J., Bidet-Caulet, A., Bertrand, O., Fonlupt, P., 2006. Listening in silence activates auditory areas: a functional magnetic resonance imaging study. J. Neurosci. 26, 273-278.

Vuilleumier, P., Bogousslavsky, J., Regli, F., 1995. Infarction of the lower brainstem. Clinical, aetiological and MRI-topographical correlations. Brain 118 (Pt. 4), 1013-1025.

Wager, T.D., Barrett, L.F., 2004. From Affect to Control: Functional Specialization of the Insula in Motivation and Regulation. Published online at PsycExtra.

Watson, P.J., Hixon, T.J., 1985. Respiratory kinematics in classical (opera) singers. J. Speech Hear. Res. 28, 104-122.

Wildgruber, D., Ackermann, H., Klose, U., Kardatzki, B., Grodd, W., 1996. Functional lateralization of speech production at primary motor cortex: a fMRI study. NeuroReport 7, 2791-2795.

Wildgruber, D., Riecker, A., Hertrich, I., Erb, M., Grodd, W., Ethofer, T., Ackermann, H., 2005. Identification of emotional intonation evaluated by fMRI. NeuroImage 24, 1233-1241.

Wilke, M., Schmithorst, V.J., 2006. A combined bootstrap/histogram analysis approach for computing a lateralization index from neuroimaging data. NeuroImage 33, 522-530.

Wolbers, T., Weiller, C., Buchel, C., 2003. Contralateral coding of imagined body parts in the superior parietal lobe. Cereb. Cortex 13, 392-399.

Yaguez, L., Nagel, D., Hoffman, H., Canavan, A.G., Wist, E., Homberg, V., 1998. A mental route to motor learning: improving trajectorial kinematics through imagery training. Behav. Brain Res. 90, 95-106.

Yoo, S.S., Lee, C.U., Choi, B.G., 2001. Human brain mapping of auditory imagery: event-related functional MRI study. NeuroReport 12, 3045-3049.

Yue, G., Cole, K.J., 1992. Strength increases from the motor program: comparison of training with maximal voluntary and imagined muscle contractions. J. Neurophysiol. 67, 1114-1123.

Zatorre, R.J., 2001. Neural specializations for tonal processing. Ann. N. Y. Acad. Sci. 930, 193-210.

Zatorre, R.J., Belin, P., 2001. Spectral and temporal processing in human auditory cortex. Cereb. Cortex 11 (10), 946-953.

Zatorre, R.J., Evans, A.C., Meyer, E., 1994. Neural mechanisms underlying melodic perception and memory for pitch. J. Neurosci. 14, 1908-1919.

Zatorre, R.J., Halpern, A.R., 2005. Mental concerts: musical imagery and auditory cortex. Neuron 47, 9-12.

Zatorre, R.J., Meyer, E., Gjedde, A., Evans, A.C., 1996. PET studies of phonetic processing of speech: review, replication, and reanalysis. Cereb. Cortex (New York, NY) 6, 21-30.

Zhang, J.X., Leung, H.C., Johnson, M.K., 2003. Frontal activations associated with accessing and evaluating information in working memory: an fMRI study. NeuroImage 20, 1531-1539. 